\title{
Nanometric-scale Characterization of Mechanical Properties of Materials by Atomic Force Microscopy
}

\author{
Ya.M.Soifer, A.Verdyan, I.Lapsker, J.Azoulay
}

Holon Academic Institute of Technology, Sciences Dept, P.O. Box 305, Holon 58102, Israel

Atomic force microscopy (AFM) provides a new method of observing microstructures in much kind of materials. The combination of a nanoindentation with topography measurements commonly allows highly localized hardness and modulus measurements to be performed on very small material volumes. In this presented paper the application of the AFM is considered for evaluation of nanohardness and Young's modulus of some alkali-halide single crystals $(\mathrm{NaCl}, \mathrm{KCl}, \mathrm{LiF})$ and high $\mathrm{T}_{\mathrm{C}}$ superconducting YBCO thin films of different thickness (from 0.05 to $1 \mu \mathrm{m}$ ) grown on different substrates. The best quality films are characterized by a transition temperature $\mathrm{T}_{\mathrm{C}}$ of $90 \mathrm{~K}$, critical current density $\mathrm{J}_{\mathrm{C}}(\mathrm{H}=0)$ of $3 \cdot 10^{7} \mathrm{~A} / \mathrm{cm}^{2}$ at $4.2 \mathrm{~K}$ and $2 \cdot 10^{6} \mathrm{~A} / \mathrm{cm}^{2}$ at $77 \mathrm{~K}$. All the procedures were performed with AFM (DI Dimension 3100) equipped with a diamond tip mounted on the end of the metal cantilever. The diamond tip was used for indenting and scratching and also for imaging sample surface using Tapping Mode. The values of nanohardness and Young's modulus were calculated directly from the load-displacement curves and quantitative study of indentation imprints were carried out by section analysis of their AFM images. For alkali-halide crystals an indentation size effect (for loads from 5 to $400 \mu \mathrm{N}$ ) was found (Fig.1). The results obtained are discussed in terms of "geometrically necessary dislocations" model proposed to interpret the indentation size effect [1]. The experimental results show a linear dependence of the square of the nanohardness $\mathrm{H}^{2}$ vs the inverse of indentation depth, $1 / \mathrm{h}$, in a good agreement with the model prediction. However the presented experimental analysis show that microscopic mechanism consideration of the indent formation is essential for quantitative study of the results.

The relationship between the mechanical properties and the microstructure features of YBCO thin films was investigated. It has been revealed that all of the YBCO films comprise well- defined $\mathrm{Cu}-$ rich precipitates on their surfaces, however their size and density depends essentially on the production method. The nanohardness and nanoscratching measurements showed that the mechanical strength of the films studied was determined by mechanical failure (see Fig.2). Surface defects (secondary phases) played an important role in the fracture process. The hardness of a film grown on $\mathrm{Al}_{2} \mathrm{O}_{3}$ substrate by magnetron sputtering was measured to be the highest one (18-20 GPa). Its Young's modulus was measured to be about $200 \mathrm{GPa}$. The nanoindentation and nanoscratching results and the role of the surface morphology are discussed in the terms of the brittle failure of ceramic materials model [2].

References

[1] W.D.Nix and H.Gao, J. Mech. Solids, 46 (1998) 411

[2] T.N. Johansen, Phys.Rev., B 60 (1999) 96290 


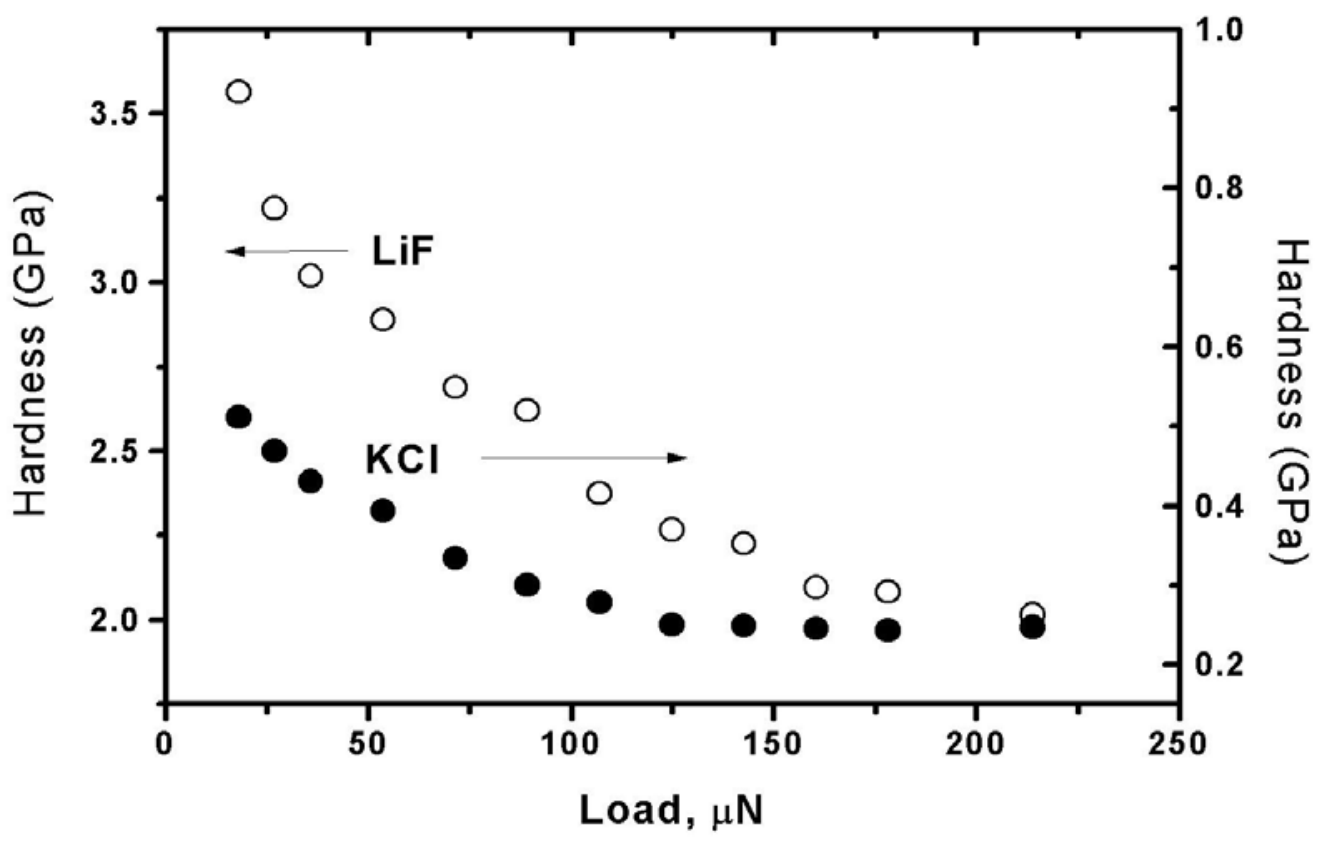

FIG.1. Load dependence of the hardness of LiF and $\mathrm{KCl}$ single crystals
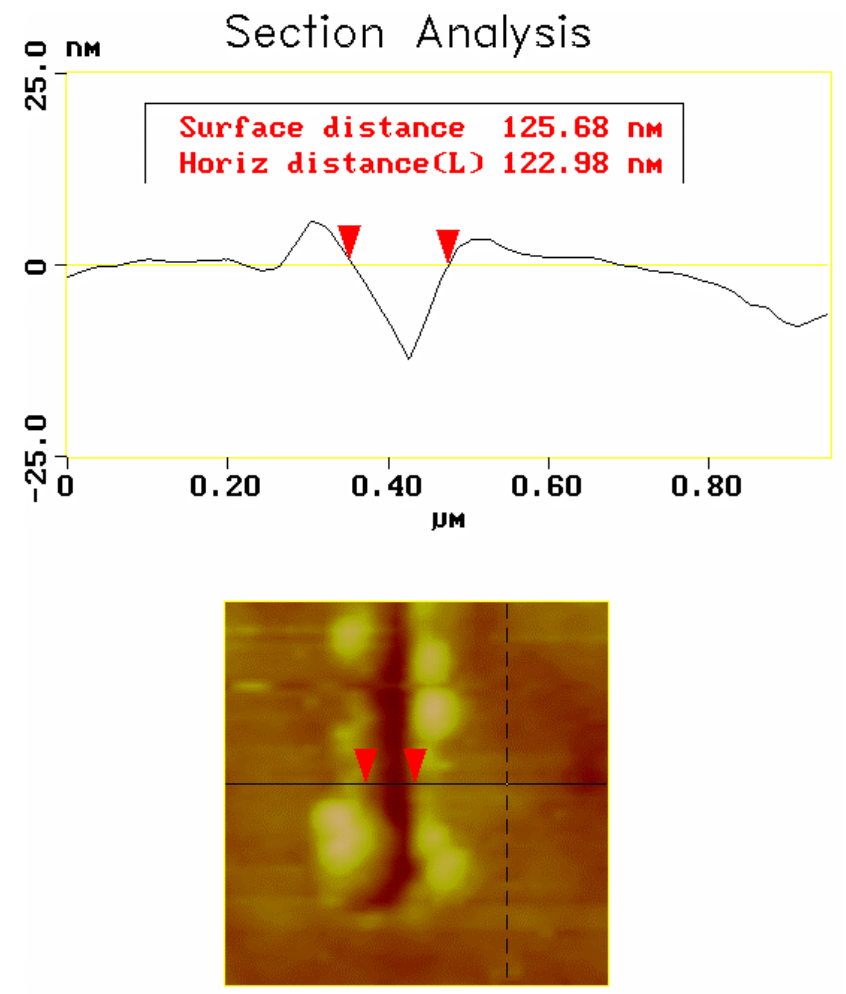

FIG.2. Scratch in YBCO thin film on $\mathrm{SrTiO}_{3}$ substrate made at the load of $90 \mu \mathrm{N}$. 